\title{
Topical propranolol improves epistaxis in patients with hereditary hemorrhagic telangiectasia - a preliminary report
}

\author{
Meir Mei-Zahav ${ }^{1,3^{*}}$ (D), Hannah Blau ${ }^{1,3}$, Elchanan Bruckheimer ${ }^{2,3}$, Eyal Zur ${ }^{4}$ and Neta Goldschmidt ${ }^{5}$
}

\begin{abstract}
Background: Severe epistaxis is often difficult to control in patients with hereditary hemorrhagic telangiectasia $(H H T)$. Propranolol has been shown to have antiangiogenic properties in vitro and in vivo and is commonly used to treat hemangiomas. We present our experience with topical nasal propranolol for the treatment of moderate to severe epistaxis in patients with HHT.

Methods: Retrospective case series. Six patients with HHT were treated with $0.5 \mathrm{~cm}^{3}$ of $1.5 \%$ propranolol gel, applied to each nostril twice daily for at least 12 weeks. Outcome measures were epistaxis severity score (ESS), hemoglobin level, and number of blood transfusions prior to and while on treatment. Local and systemic side effects were recorded.

Results: The mean duration of treatment was $30 \pm 5.6$ weeks. A significant improvement in the ESS was found in all patients, with a mean decrease from $6.4 \pm 2.1$ at treatment onset to $3.5 \pm 1.7$ at 12 weeks $(p=0.028)$.

Hemoglobin level increased significantly from $8.4 \pm 3.1$ to $11.0 \pm 1.8 \mathrm{~g} / \mathrm{dL}$ at 12 weeks $(p=0.043)$. The mean number of blood transfusions decreased from $4.5 \pm 4.9$ before treatment to $2.5 \pm 2.9$ at 12 weeks and $0.3 \pm 0.8$ at 24 weeks, but the difference did not reach statistical significance ( $p=0.109$ for both). No significant side effects of treatment were recorded.
\end{abstract}

Conclusions: These preliminary results suggest that topical propranolol may be effective for the treatment of epistaxis in patients with HHT. A prospective controlled trial is required to confirm our findings.

Keywords: Hereditary hemorrhagic telangiectasia, Epistaxis, Propranolol, Anti-angiogenesis

\section{Background}

Hereditary hemorrhagic telangiectasia (HHT, OslerWeber-Rendu disease) is characterized by the presence of abnormally dilated blood vessels, ranging from telangiectases in mucocutaneous tissues to large arteriovenous malformations in various organs including the lung, brain, and liver. The telangiectases tend to rupture, resulting in recurrent nasal or gastrointestinal bleeding [1]. In the majority of patients, the dysregulated angiogenesis and unbalanced generation of abnormal blood vessels are caused by mutations in the genes encoding endoglin and activin-like kinase 1 receptor (ACVLR1),

\footnotetext{
* Correspondence: mmeizahav@gmail.com

${ }^{1}$ The National HHT Center, Pulmonary Institute, Schneider Children's Medical Center of Israel, 49202 Petach Tikva, Israel

${ }^{3}$ Sackler Faculty of Medicine, Tel Aviv University, Tel Aviv, Israel

Full list of author information is available at the end of the article
}

components of the transforming growth factor- $\beta$ receptor complex [1, 2]. Findings of increased levels of vascular endothelial growth factor (VEGF), a major angiogenic factor, in the blood and tissue of patients with HHT [3] suggest that it plays a role in the abnormal angiogenesis [2]. Therefore, VEGF may serve as a potential therapeutic target in HHT [4-6].

Propranolol is a nonselective beta blocker routinely used to treat hemangiomas in infants. It exerts an antiangiogenic effect via apoptosis of endothelial cells and reduction of VEGF tissue expression [7]. Besides the few reports of topical timolol as a means of controlling epistaxis $[8,9]$, clinical data on propranolol as a therapeutic agent in HHT are scarce, and there are no reports of topical propranolol for epistaxis in this setting. The aim of the present case series was to describe our initial 
experience with the nasal application of propranolol gel to treat epistaxis in patients with HHT.

\section{Methods \\ Patients}

Between January 2014 and September 2015, patients with HHT who presented with moderate to severe epistaxis as evaluated by the Epistaxis Severity Score (ESS) [10] were treated with topical propranolol for a period of at least 12 weeks. As the treatment was novel and off label, we followed the patients carefully for safety and efficacy using a defined protocol. The inclusion criteria were: a clinical or genetic diagnosis of HHT; moderate to severe epistaxis (ESS- 4-10); failure of standard measures to control the bleeding including repeated cauterizations and laser applications, local or systemic tranexamic acid and in some patients, tamoxifen therapy; and no improvement with moisturizing gels administered locally for at least 8 weeks. The exclusion criteria were: congestive heart failure, baseline bradycardia, or any other contraindication for beta blocker treatment; on-going beta blocker therapy; any nasal surgery, laser treatment or cauterizations in the 3 months prior to treatment. The washout period after stopping beta blocker therapy was at least a month. Eligible patients were instructed to continue all other treatments with no change and to refrain from applying other local nasal agents.

Patients were instructed to visit their health care provider for blood pressure and heart rate measurements while receiving the propranolol gel therapy. Measurements were performed weekly the first 4 weeks and monthly thereafter.

For the present trial, the patients were seen in clinic at treatment initiation and every 3 months thereafter. The ESS was assessed at initiation of treatment as a score of 4-10 was a requirement for eligibility. In addition, since propranolol gel was a novel treatment we compared ESS and hemoglobin at onset of therapy and at 12 weeks to assess treatment efficacy.

\section{Medication}

Treatment consisted of the application of $0.5 \mathrm{~cm}^{3}$ of $1.5 \%$ propranolol gel to each nostril twice daily for at least 12 weeks. The gel was prepared by a compounding pharmacy and contained propranolol hydrochloride 1.5\% in isotonic and preserved hyperomellose gel. The gel was supplied with a plastic funnel-shaped guide attached to a syringe to avoid trauma to the nasal mucosa. Patients were instructed to insert the guide gently $0.5-1 \mathrm{~cm}$ into each nostril, to inject the gel into the nasal space and to inhale through the nostrils in order to spread the gel on the mucosa. Patients were instructed to do so in front of a mirror in order to apply the exact amount of gel prescribed.
The medication was prepared and supplied by one of the authors (EZ). A prescription for each patient was sent to the pharmacist monthly by 2 of the authors (NG and $M M)$. As this was a new off-label therapy, patients reported use of the medication at each follow up visit, every 3 months.

Administration of the medication was approved by the hospital pharmaceutical committee. In accordance with the regulations for off-label use of a drug in Israel, all patients received a detailed explanation regarding the drug, and agreed to its off-label use.

\section{Outcome measures}

The primary outcome measure was the change in ESS score. Secondary outcome measures were the change in hemoglobin and the change in the number of blood transfusions during 12 weeks after onset of therapy compared to the 12 weeks prior to therapy. The number of transfusions required in the 6 months following onset of therapy were also recorded when applicable.

\section{Statistical analysis}

Continuous variables are summarized as mean and standard deviation. Wilcoxon signed-rank test was used to evaluate the difference between pre- and posttreatment ESS, hemoglobin levels, and transfusion requirements.

\section{Results}

Nine patients were initially enrolled in the study. Of these, two had been scheduled for Young's nasal closure prior to propranolol treatment, and despite an improvement after 4-8 weeks of treatment with propranolol they decided to undergo nasal closure. Since their ESS did not reflect 12 weeks of treatment, they were excluded from the analysis. A third patient was excluded because he had started systemic bevacizumab treatment for high cardiac output failure secondary to hepatic arteriovenous malformations.

The remaining six patients formed the study group. Table 1 summarizes their characteristics and disease course. The mean duration of treatment was $30 \pm 5.6$ weeks. At 12 weeks, there was a decrease in mean ESS from $6.4 \pm 2.1$ to $3.5 \pm 1.7(p=0.028)$. The main improvements in the ESS parameters were a decrease in epistaxis frequency and duration. In three patients, the frequency of epistaxis episodes decreased from several times a day to less than once daily, and in two patients, the duration of the epistaxis episodes decreased from more than $30 \mathrm{~min}$ to less than $15 \mathrm{~min}$. Three patients reported a change in epistaxis intensity from pouring and gushing to milder non-pouring bleeds. The mean hemoglobin level increased from $8.4 \pm 3.1 \mathrm{~g} /$ 
Table 1 Clinical characteristics, treatment, and outcome of six patients with HHT treated with topical propranolol for epistaxis

\begin{tabular}{|c|c|c|c|c|c|c|c|}
\hline \multirow[t]{2}{*}{ Pt. no. } & \multicolumn{3}{|c|}{ Demographics \& HHT features } & \multicolumn{4}{|c|}{ Topical propranolol treatment - duration and outcome measures } \\
\hline & Age/ gender (M/F) & HHT mutation & Other HHT features & $\begin{array}{l}\text { Treatment duration } \\
\text { (wks) }\end{array}$ & $\begin{array}{l}\text { ESS before/ after } \\
12 \text { wks treatment }\end{array}$ & $\begin{array}{l}\mathrm{Hb}(\mathrm{gr} \%) \text { before/after } \\
12 \text { wks treatment }\end{array}$ & $\begin{array}{l}\text { PC before treatment/after } \\
12 \text { wks/after } 24 \text { wks }\end{array}$ \\
\hline 1 & $72 / \mathrm{M}$ & Endoglin & PAVMs, Gl bleed & 48 & $7.3 / 1.5$ & $7.4 / 10.9$ & $10 / 3 / 0$ \\
\hline 2 & $55 / F$ & Endoglin & HAVMs, GI bleed & 12 & $4.4 / 1.9$ & $12 / 12$ & - \\
\hline 3 & $68 / F$ & ACVRL-1 & PAVMs, HAVMs & 38 & $10 / 5.9$ & $5.4 / 9.9$ & $9 / 6 / 0$ \\
\hline 4 & $41 / \mathrm{M}$ & ACVRL-1 & PAVMs & 34 & $4.4 / 2.5$ & $12.5 / 14$ & - \\
\hline 5 & $37 / F$ & ACVRL-1 & None & 26 & $6.2 / 4.2$ & $6.1 / 10$ & - \\
\hline 6 & $76 / F$ & Not done & HAVMs & 26 & $6.4 / 4.9$ & $7.1 / 9.1$ & $8 / 6 / 2$ \\
\hline$p$ & & & & & $0.028^{\mathrm{a}}$ & $0.043^{\mathrm{a}}$ & $\begin{array}{l}0.109^{\mathrm{a}}(12 \text { weeks }) 0.109^{\mathrm{a}} \\
(24 \text { weeks })\end{array}$ \\
\hline
\end{tabular}

Wilcoxon signed-rank test

Abbreviations: ESS epistaxis severity score, Gl gastrointestinal, HAVMs hepatic arteriovenous malformations, Hb hemoglobin, PAVMs pulmonary arteriovenous malformations, $P C$ packed red cells

$\mathrm{dL}$ at treatment initiation to $11 \pm 1.8 \mathrm{~g} / \mathrm{dL}$ at 12 weeks of treatment $(p=0.043)$.

Patients with gastrointestinal bleeding (nos. 1 and 2, Table 1) did not experience a significant change in their gastrointestinal bleeds, suggesting the improvement in their hemoglobin levels was due to the decrease in nasal bleeding.

Blood transfusions were given as needed. Three patients required 8-10 transfusions of packed red cells each in the 12 weeks prior to the initiation of topical propranolol treatment (Table 1). The mean number of blood transfusions decreased from $4.5 \pm 4.9$ in the 12 weeks prior to treatment to $2.5 \pm 2.9$ at 12 weeks and $0.3 \pm 0.8$ at 24 weeks of treatment. The difference, however, did not reach statistical significance $(p=0.109$ for both). On reviewing the data, we found that no transfusion had been given in the week prior to the hemoglobin measurement. However, as this study was retrospective, it was difficult to isolate the effect of any previous transfusion on the hemoglobin level.

All patients took iron supplements before and while on treatment. They were not prescribed any other treatment for epistaxis during the propranolol treatment period.

Patients were contacted monthly to monitor side effects and were reminded to record blood pressure and heart rate at their local clinic. Blood pressure and heart rate remained stable in all cases, and no significant side effects were reported. One patient complained of a burning sensation at treatment initiation which resolved within a few days.

\section{Discussion}

Epistaxis in HHT can be severe, leading to secondary iron deficiency anemia and transfusion dependency [1], and it may not respond to standard measures. Treatment with different antiangiogenic agents has recently been proposed. Bevacizumab is so far the most studied [2, 4-6].

Topical propranolol is in widespread use for the treatment of infantile hemangiomas. Infantile hemangiomas share several characteristics with HHT, namely dysregulated angiogenesis and high levels of tissue VEGF [11]. Indeed, in vitro studies have reported that propranolol decreased the migration and angiogenesis of both normal as well as HHT endothelial cells [12]. Recently, oral propranolol was found to be effective in treating epistaxis in patients with HHT [13]. The present study is the first to show that epistaxis in HHT may also be relieved with propranolol gel. We observed a mean reduction of $3 \pm 1.6$ in the ESS after 12 weeks of treatment, which is considerably greater than the 0.71 change in ESS that was recently suggested to be clinically significant [14]. Other outcome measures were in concurrence with the decrease in ESS: hemoglobin level increased and the transfusion requirement decreased.

Propranolol is efficiently absorbed when applied to the nasal mucosa [15]. Systemic propranolol decreases heart rate and cardiac output resulting in decreased blood pressure. We did not observe these side effects in our patients, probably owing to the low daily cumulative dose of propranolol used $(30 \mathrm{mg})$, which is considered sub-therapeutic for oral treatment of cardiovascular diseases in adults. This safety profile is in contrast to the significant side effects of other antiangiogenic medications used in patients with HHT [2, 4-6]. Furthermore, the cost of propranolol is very low.

Our study is limited by its retrospective nature. Although it is possible that the moisturizing effect of propranolol gel contributed to the reduction in epistaxis, our patients were instructed to use moisturizing gel for at least 2 months prior to propranolol treatment, and it failed to lead to significant improvement. An improvement in epistaxis parameters was also noted in the three patients who were excluded, but their period of 
treatment with propranolol was too short for analysis. These patients had either been scheduled for other treatments prior to propranolol initiation or were switched to systemic antiangiogenic agents to treat other symptoms, and propranolol was used as a bridge.

A controlled trial is required to further assess the safety and efficacy of propranolol gel for epistaxis in HHT.

\section{Conclusions}

Our preliminary results suggest that nasal propranolol gel may have a place in the treatment of HHT-related epistaxis. A prospective randomized trial is planned to further assess the clinical efficacy and safety of topical propranolol for this purpose.

\section{Abbreviations \\ ESS: Epistaxis severity score; $\mathrm{HHT}$ : Hereditary hemorrhagic telangiectasia; VEGF: Vascular endothelial growth factor}

\section{Acknowledgments}

Not applicable.

Funding

No funding.

\section{Availability of data and materials}

The datasets supporting the conclusions of this article are included within the article and are available from the corresponding author on reasonable request.

\section{Authors' contributions}

MMZ- designed the study, collected and analyzed the data and prepared the manuscript. HB- analyzed the data and had a major contribution in writing the manuscript. EB- analyzed the data and had a major contribution in writing the manuscript. EZ- designed the study, analyzed the data and revised the manuscript. NG- designed the study, analyzed the data and had a major contribution in writing the manuscript. All authors read and approved the final manuscript.

\section{Authors' information}

Meir Mei-Zahav - Director of the National HHT Center, Schneider Children's Medical Center of Israel and Sackler School of Medicine, Tel Aviv University, Israel. Hannah Blau - Director, Pulmonary Institute, Schneider Children's Medical Center of Israel and Sackler School of Medicine, Tel Aviv University, Israel. Elchanan Bruckheimer -Director, Cardiac Catheterization Laboratories, Schneider Children's Medical Center of Israel and Sackler School of Medicine, Tel Aviv University, Israel.

Eyal Zur - Compounding Pharmacist and Scientific Manager, Super-Pharm Professional Laboratories, Israel.

Neta Goldschmidt- Senior physician, Department of Hematology, HadassahHebrew University Medical Center, Jerusalem, Israel.

\section{Ethics approval and consent to participate}

The study was approved by the ethics committee of Rabin Medical Center (approval no. RMC 0230-15).

\section{Consent for publication}

Not applicable.

\section{Competing interests}

The authors declare that they have no competing interests.

\section{Author details}

${ }^{1} T$ The National HHT Center, Pulmonary Institute, Schneider Children's Medical Center of Israel, 49202 Petach Tikva, Israel. ${ }^{2}$ Cardiology Institutes, Schneider Children's Medical Center of Israel, Petach Tikva, Israel. ${ }^{3}$ Sackler Faculty of Medicine, Tel Aviv University, Tel Aviv, Israel. ${ }^{4}$ Super-Pharm Professional -
Central Compounding Pharmacy, Petach Tikva, Israel. ${ }^{5}$ Department of Hematology, Hadassah-Hebrew University Medical Center, Jerusalem, Israel.

Received: 3 May 2017 Accepted: 26 September 2017

Published online: 04 October 2017

References

1. McDonald J, Bayrak-Toydemir P, Pyeritz RE. Hereditary hemorrhagic telangiectasia: an overview of diagnosis, management, and pathogenesis. Genet Med. 2011;13(7):607-16.

2. Ardelean DS, Letarte M. Anti-angiogenic therapeutic strategies in hereditary hemorrhagic telangiectasia. Front Genet. 2015;6:35

3. Sadick H, Naim R, Gössler U, Hörmann K, Riedel F. Angiogenesis in hereditary hemorrhagic telangiectasia: VEGF165 plasma concentration in correlation to the VEGF expression and microvessel density. Int J Mol Med. 2005;15(1):15-9.

4. Garg N, Khunger M, Gupta A, Kumar N. Optimal management of hereditary hemorrhagic telangiectasia. J Blood Med. 2014;5:191-206.

5. Dupuis-Girod S, Ginon I, Saurin JC, Marion D, Guillot E, DeCullier E, et al. Bevacizumab in patients with hereditary hemorrhagic telangiectasia and severe hepatic vascular malformations and high cardiac output. JAMA. 2012; 307(9):948-55.

6. Riss D, Burian M, Wolf A, Kranebitter V, Kaider A, Arnoldner C. Intranasal submucosal bevacizumab for epistaxis in hereditary hemorrhagic telangiectasia: a double-blind, randomized, placebo-controlled trial. Head Neck. 2015;37(6):783-7.

7. Storch $\mathrm{CH}$, Hoeger PH. Propranolol for infantile haemangiomas: insights into the molecular mechanisms of action. Br J Dermatol. 2010;163(2):269-74.

8. Epperla N, Brilliant $\mathrm{MH}$, Vidaillet $\mathrm{H}$. Topical timolol for treatment of epistaxis in hereditary haemorrhagic telangiectasia associated with bradycardia: a look at CYP2D6 metabolising variants. BMJ Case Rep. 2014;2014

9. Olitsky SE. Topical timolol for the treatment of epistaxis in hereditary hemorrhagic telangiectasia. Am J Otolaryngol. 2012;33(3):375-6.

10. Hoag JB, Terry P, Mitchell S, Reh D, Merlo CA. An epistaxis severity score for hereditary hemorrhagic telangiectasia. Laryngoscope. 2010;120(4):838-43.

11. Przewratil P, Sitkiewicz A, Andrzejewska E. Local serum levels of vascular endothelial growth factor in infantile hemangioma: intriguing mechanism of endothelial growth. Cytokine. 2010;49(2):141-7.

12. Albiñana $V$, Recio-Poveda L, Zarrabeitia R, Bernabéu C, Botella LM Propranolol as antiangiogenic candidate for the therapy of hereditary haemorrhagic telangiectasia. Thromb Haemost. 2012;108(1):41-53.

13. Contis A, Gensous N, Viallard JF, Goizet C, Leaute-Labreze C, Duffau P. Efficacy and safety of propranolol for epistaxis in hereditary haemorrhagic telangiectasia: retrospective, then prospective, study in a total of 21 patients. Clin Otolaryngol. 2017;42(4):911-7.

14. Yin LX, Reh DD, Hoag JB, Mitchell SE, Mathai SC, Robinson GM, et al. The minimal important difference of the epistaxis severity score in hereditary hemorrhagic telangiectasia. Laryngoscope. 2016;126(6):1029-32.

15. Hussain A, Foster T, Hirai S, Kashihara T, Batenhorst R, Jones M. Nasal absorption of propranolol in humans. J Pharm Sci. 1980;69(10):1240.

Submit your next manuscript to BioMed Central and we will help you at every step:

- We accept pre-submission inquiries

- Our selector tool helps you to find the most relevant journal

- We provide round the clock customer support

- Convenient online submission

- Thorough peer review

- Inclusion in PubMed and all major indexing services

- Maximum visibility for your research

Submit your manuscript at www.biomedcentral.com/submit 